\title{
Anesthesia-Resuscitation and Prognostic Factors of Morbidity and Mortality of Eclampsia: A Study in Cumilla Medical College, Cumilla, Bangladesh
}

\author{
Md. Kamrul Hossain ${ }^{1 *}$, Md. Delwar Hossain ${ }^{2}$, Mohammad Shakhawat Hossain ${ }^{3}$, Md. Atower Rahman ${ }^{4}$ \\ ${ }^{1}$ Assistant Professor, Departmnt of Anaesthesiology \& ICU, Cumilla Medical College, Cumilla, Bangladesh \\ ${ }^{2}$ Assistant Professor, Departmnt of Anaesthesiology \& ICU, Cumilla Medical College, Cumilla, Bangladesh \\ ${ }^{3}$ Assistant Professor, Departmnt of Anaesthesiology, Cumilla Medical College, Cumilla, Bangladesh \\ ${ }^{4}$ Associated Professor, Departmnt of Anaesthesiology \& ICU, Cumilla Medical College, Cumilla, Bangladesh
}

DOI: $\underline{10.36348 / \text { sjmps.2020.v06i09.005 }}$ | Received: 04.09.2020 | Accepted: 13.09.2020 | Published: 30.09 .2020

*Corresponding author: Md. Kamrul Hossain

\section{Abstract}

Introduction: Eclampsia, a major neurological complication of pre-eclampsia, is defined by a convulsive manifestation and /or consciousness disorder occurring in a preeclampsia context and cannot be attributed to a pre-existing neurological problem. Pre eclampsia is a leading cause of maternal morbidity and mortality. Substandard care is often present and many deaths are preventable. The severity of this pathology is correlated with visceral neurological, renal, hepatic and / or hematological involvement. Objective: To study the peculiarities of anesthesia-resuscitation and the prognostic factors of morbidity and mortality of eclampsia in the intensive care unit of the Anaesthesiology Dept. Cumilla Medical College, Cumilla, Bangladesh. Materials and Methods: All patients admitted to resuscitation for management of eclampsia from 1 January to 31 December 2018 were included. We studied the clinical, therapeutic, evolutionary and prognostic factors of morbidity and mortality. Results: We collected 51 cases of eclampsia for 5000 deliveries in the study (incidence of $1 \%)$. The average age of the patients was 22.23 years. Primiparity was found in 28 patients $(54.9 \%)$. Antenatal consultations were effective in 4 patients $(7.8 \%)$. Consciousness was clear at admission in 42 patients $(82.36 \%)$ and for one patient a Glasgow score $<8$ was reported (1.96\%). Severe hypertension was observed in $27.4 \%$ of cases. A ventilation intubation of 03 days was required in one patient in $1.9 \%$ of cases. Caesarean was the mode of delivery in $56.8 \%$ of cases and vaginal delivery was performed in $43 \%$ of cases. General anesthesia was doing in 20 patients (68.9\%) and spinal anesthesia was performed in 9 patients $(31 \%)$. Maternal complications were represented by: Postpartum acute renal failure (13.7\%), Hellp syndrome (11.7\%), and coagulopathy (15.6\%). Prematurity was found in 14 neonates (13.7\%), perinatal mortality was $9.8 \%$ and the maternal mortality rate was $5.8 \%$. Conclusion: Eclampsia is still responsible for high maternal and infant mortality. The association of two or even more serious factors is very important in this mortality.

Keywords: Eclampsia; Anesthesiology; Prognostic factors of morbidity and mortality.

Copyright @ 2020: This is an open-access article distributed under the terms of the Creative Commons Attribution license which permits unrestricted use, distribution, and reproduction in any medium for non-commercial use (NonCommercial, or CC-BY-NC) provided the original author and source are credited.

\section{INTRODUCTION}

Pre- eclampsia is a leading cause of maternal morbidity and mortality. Substandard care is often present and many deaths are preventable. Eclampsia, a major neurological complication of pre-eclampsia, is defined by a convulsive manifestation and/or consciousness disorder occurring in a preeclampsia context and cannot be attributed to a pre-existing neurological problem [1]. It has remained as a major public health threat both in developed and developing countries, contributing to maternal and perinatal morbidity and mortality. Preeclampsia precursor to eclampsia ranges between $2 \%$ to $10 \%$ of total pregnancies worldwide. The severity of this pathology is correlated with visceral neurological, renal, hepatic and/or hematological involvement. The morbidity and mortality of eclampsia is still high in Africa countries [2]. The objective of this study was to evaluate the clinical aspects, the therapeutic management, the evolutionary aspects and the prognostic factors of morbidity and mortality of eclampsia in the intensive care unit of the Anaesthesiology Dept. Cumilla Medical College, Cumilla, Bangladesh. In our study, the high rate of general anesthesia is explained by the fear of performing spinal punctures in case of coagulopathy or thrombocytopenia, especially because delays in 
obtaining blood sample results (NFS, TP) do not favor this risk taking. However, no case of Mendelson's syndrome was seen. Eclampsia is the ultimate stage of the Vasculo-renal complications of pregnancy. Preeclampsia is a multisystem disease unique to human pregnancy characterised by hypertension and organ system involvement. The disease is responsible for considerable morbidity and mortality, complicating 5$8 \%$ of pregnancies. Deaths are due to intracranial haemorrhage and cerebral infarction, acute pulmonary oedema, respiratory failure and hepatic failure or rupture [3, 4]. However, due to limited number of facilities-based service provision, availability, and affordability of patients a limited and/or no studies were conducted investigating fetal and maternal outcome of eclampsia in Bangladesh. Considering the scant amount of evidence we carried out this study in an attempt to assess perinatal outcome relating to clinical types and management of eclampsia. Severe maternal complications include antepartum haemorrhage due to placental abruption, eclampsia, cerebrovascular accidents, organ failure and disseminated intravascular coagulation [3-6]. Pre- eclampsia is the leading cause of fetal growth restriction, intrauterine fetal demise and preterm birth [4-7]. Women who experience preeclampsia are at increased risk of hypertension, cerebrovascular disease and ischaemic heart disease, in later life. Anaesthetists are frequently involved in the multi- disciplinary management of critically ill women with pre- eclampsia, and clinical practice should be based on current scientific evidence. This article was developed as there was a need to provide a current succinct summary of the anaesthetic issues relating to the care of women with pre- eclampsia relevant for anaesthetists. This review covers the management of women with pre- eclampsia, including eclampsia and the syndrome of haemolysis with elevated liver enzymes and low platelets (HELLP) in the peripartum period, which is specifically relevant to anaesthetists. It does not cover prevention, screening, risk factors, pathophysiology, and prognosis or long- term management of the disease.

\section{Material AND Methods}

This is a retrospective, descriptive and analytical study of all patients admitted for eclampsia from January 1 to December 31, 2018 in the multipurpose intensive care unit of the Anaesthesiology Dept. Cumilla Medical College, Cumilla, Bangladesh. The diagnosis of eclampsia was based on the occurrence of peripartum seizures in a woman whose history and examination revealed no other cause for the convulsion. All patients with eclampsia were treated according to the management protocol, namely: stabilization (peripheral venous catheter, oxygen therapy, Guedel cannula, lateral safety position, standard monitoring), administration of $4 \mathrm{~g} \mathrm{SMgO} 4$ in 20 minutes then $1 \mathrm{~g} / \mathrm{h}$ for $48 \mathrm{~h}$, control of arterial hypertension / Nicardipine, childbirth by the quickest method, admission for resuscitation. All patients had blood samples analyzed for: azotemia, creatinine, blood count with platelet count, hemostasis balance (TP and INR, TCA), bilirubinemia and liver aminotransferases. An additional assessment was requested for every suspicion of HELLP syndrome (fibrinogen, D-Dimer, PDF and hepatic ultrasound). A cerebral scan was requested in the presence of severe neurological symptoms: deep coma after a seizure, deficiency signs, neurovegetative symptoms (respiratory distress, irregular blood pressure and/or heart rate). Data was collected from medical records, reference cards and hospital records. They were then entered in an Epi info data entry form. We assessed on Epi-Info 7.1: the incidence of eclampsia, age, parity, gestational age, time of onset of seizure, anesthesia technique, systolic and diastolic blood pressures (PAS-PAD) on admission, Glasgow coma scale, the presence of oligo-anuria, maternal complications (acute renal failure, Hellp Syndrome, Coagulopathy, subcapsular hematoma of the liver, acute edema of the lungs, cerebro-meningeal hemorrhages); fetal complications, Apgar score at birth, maternal and perinatal mortality.

\section{Data Analysis}

The descriptive analysis was done on Epi-info 7.1 and the illustrations on Excel 2016. The analysis was univariate then bivariate. The alpha was set at 5\%, that is, the p-value was considered significant whenever it was less than 0.05 . Prolonged endotracheal intubation (3 days) was necessary in one patient, or in $1.9 \%$ of cases.

\section{RESUlTS}

A total of 51 cases of eclampsia for 5000 deliveries were treated during this period, i.e. an incidence of 10 cases of eclampsia /1000 deliveries. The mean age of the patients was 22.23 years, with a range of 14 to 36 , and a standard deviation of 5.59. The most represented age group was 14-19 years old, in $39.2 \%$ of cases. Primiparity was found in 28 patients, $54.9 \%$ of the time. The prenatal consultations were effective in 4 patients, in $7.8 \%$ of the cases. Pregnancy was conducted to completion for 20 patients in $39 \%$ of cases. The patients came from the maternity ward in $47.1 \%$ (24 cases) and peripheral health facilities in $52.9 \%$ (27 patients). The first episodes of seizures occurred in antepartum in 31 patients, in $61 \%$ of cases. In 20 patients the seizure was reported postpartum, i.e. in $39 \%$ of cases. In our series, 24 patients had their first seizure in the obstetrics and gynecology department, $47 \%$ of the time, and in 15 patients, the anamnesis had a convulsive seizure at home $(29.4 \%)$. Consciousness was clear at admission (15/15 Glasgow score) in 42 patients, i.e. in $82.36 \%$ of cases, and a coma was reported in one patient (Glasgow score <8), i.e. in 1.96 $\%$ of cases. At admission, minimal arterial hypertension (defined as PAS between 140 and $159 \mathrm{mmHg}$ and/or 
PAD between 80 and $89 \mathrm{mmHg}$ according to the NYHA classification) was observed in 10 patients, i.e. in $19.6 \%$ of cases. Moderate arterial hypertension (PAS between 160 and $179 \mathrm{mmHg}$ and/or a DBP between 90 and $99 \mathrm{mmHg}$, according to the NYHA) was found in 15 patients, i.e. in $29.4 \%$ of cases. Severe arterial hypertension (NO greater than or equal to $180 \mathrm{mmHg}$ and/or PAD greater than or equal to $100 \mathrm{mmHg}$ according to NYHA) was objectified in 14 patients, i.e. in $27.4 \%$ of cases. However, the blood pressure at admission was normal in 12 patients, i.e. in $23.5 \%$ of cases. Oliguria and / or oligo-anuria defined by diuresis $<0.5 \mathrm{ml} / \mathrm{kg} / \mathrm{ha}$ was observed in 6 patients, i.e. in $11.7 \%$ of cases and proteinuria greater than 2 crosses was found in 10 patients, i.e. in $19.5 \%$ of cases. The maintenance treatment consisted of the administration of $1 \mathrm{~g} / \mathrm{h}$ of magnesium sulphate in 45 patients, i.e. in $88.2 \%$ of the cases. However, diazepam in an electric syringe was necessary in 3 patients, i.e. in $5.8 \%$ of cases. Nicardipine monotherapy with an electric syringe was used in the treatment of hypertension in 20 patients, i.e. in $39.2 \%$ of cases and a combination therapy (Nicardipine-clonidine) was required in one patient, i.e. in $1.9 \%$ of cases. Endotracheal intubation of 3 days was necessary in one patient, i.e. in $1.9 \%$ of cases. Caesarean sections were performed in 29 patients, i.e. $56.8 \%$ of the time, and vaginal delivery was reported in 22 , i.e. $43 \%$ of the cases. General anesthesia was the anesthetic technique of choice in 20 patients, i.e. in $68.9 \%$ of cases and spinal anesthesia was performed in 9 patients, i.e. in $31 \%$ of cases. Postpartum acute renal failure was found in 7 patients, i.e. in $13.7 \%$ of cases. The Hellp syndrome was noted in 6 patients, i.e. in $11.7 \%$ of cases, coagulopathy was reported in 8 patients or in $15.6 \%$ of cases, hemorrhagic stroke and magnesium sulfate overdose (via slow intravenous calcium administration) were found in one patient respectively, i.e. in $1.9 \%$ of cases respectively. The evolution has objectified 3 cases of death, a mortality rate of $5.8 \%$. Prematurity was found in 14 neonates, i.e. in $13.7 \%$ of cases and perinatal mortality in 5 out of 51 cases, i.e. a perinatal mortality rate of $9.8 \%$. Acute fetal distress and prematurity were the causes of death in $60 \%$ and $20 \%$ of cases, respectively. In bivariate analysis, pregnancy was associated with the occurrence of a HELLP syndrome ( $\mathrm{p}$-value $=0.02$ ) and the occurrence of stroke-type complications ( $\mathrm{p}$-value = 0.01). Multiparity was also associated with coagulopathy and HELLP syndrome ( $\mathrm{p}$-value $=0.02$ ). The altered state of consciousness (Glasgow score <15) was associated with acute renal failure ( $p$-value $=0.01$ and the combination of complications of IRA+coagulopathy $\quad(\mathrm{p}$-value $=\quad 0.005)$. $\quad$ Maternal mortality was also associated with cerebro-meningeal hemorrhage, complications of IRA+HELLP syndrome $(\mathrm{p}<0.05)$ and coagulopathy $(\mathrm{p}>0.05)$.

Table-1: Distribution of complications as a function of evolution ( $N=50)$

\begin{tabular}{|l|l|l|l|l|l|}
\hline Complications & Number of parturients & \multicolumn{2}{|l|}{ Evolution : Favorable death } & Percentage \\
\hline Acute renal failure & 7 & 7 & - & & $13.7 \%$ \\
\hline Hellp syndrome & 6 & 6 & - & & $11.7 \%$ \\
\hline Acute renal failure + Hellp & 2 & - & 2 & $(\mathrm{p}<0.05)$ & $3.9 \%$ \\
\hline Coagulopathy & 8 & 7 & 1 & & $15.6 \%$ \\
\hline Cerebro-meningeal hemorrhage & 1 & - & 1 & $(\mathrm{p}<0.05)$ & $1.9 \%$ \\
\hline Overdose with magnesium sulphate & 1 & 1 & - & & $1.9 \%$ \\
\hline Hellp: Hemolysis, Elevated Liver enzymes, Low Platelet count \\
\hline
\end{tabular}

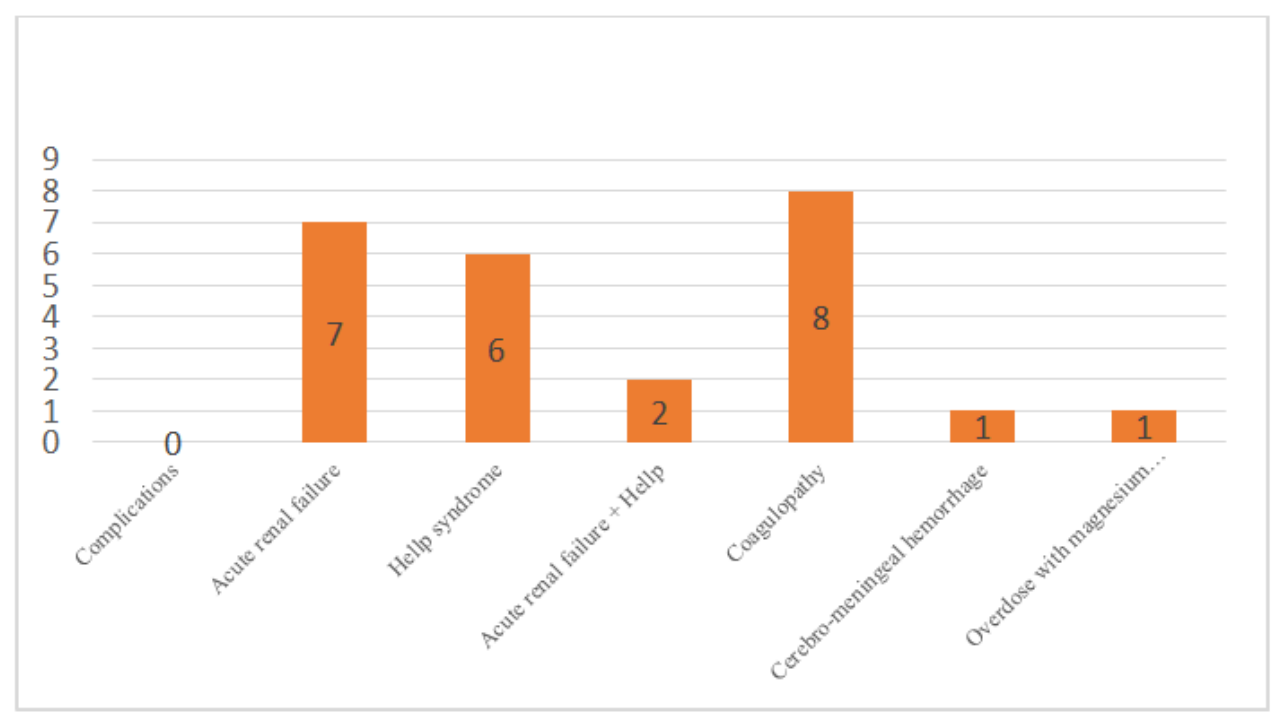

Fig-1: Number of parturients Complications 


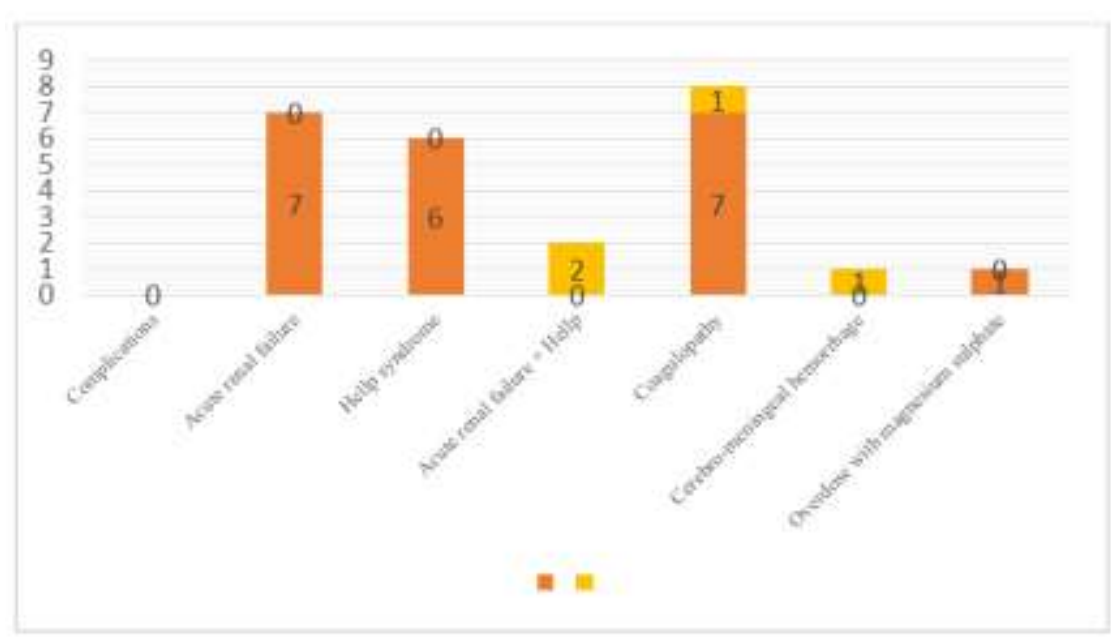

Fig-2: Number of Complications Evolution: Favorable death

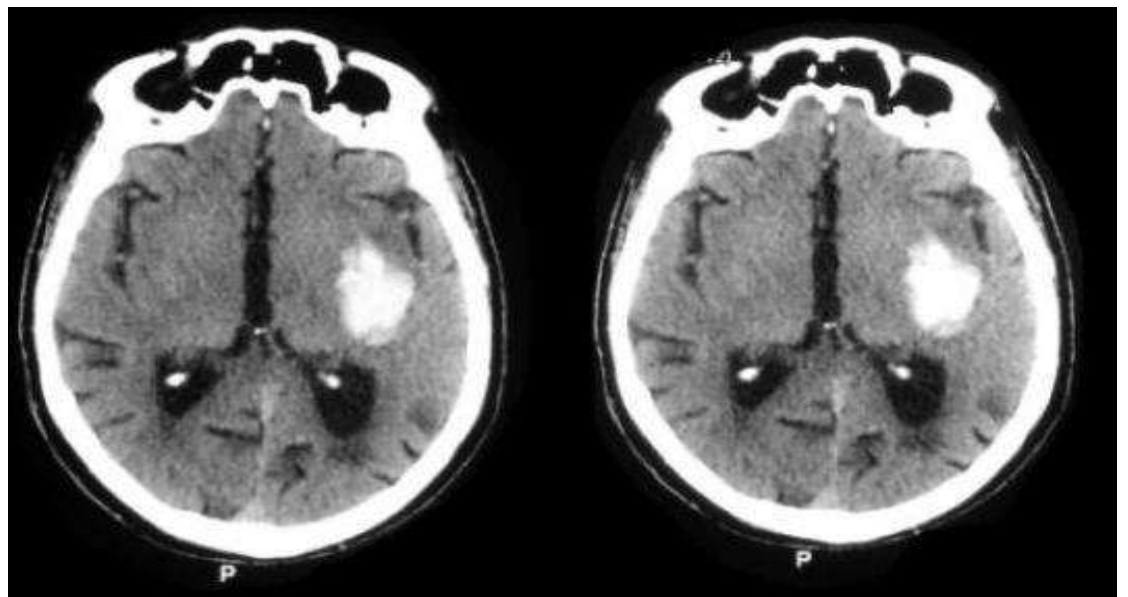

Fig-3: Non-injected brain scanner showing intraparenchymal hematoma in an eclamptic patients

\section{DisCUSSION}

Eclampsia is a serious complication of preeclampsia that can be life-threatening. The annual incidence of eclampsia in Saint Louis remains high at the rate of 10 cases/1000 deliveries, i.e. in $1 \%$ of cases. The analysis of literature data found a variable incidence in developing countries with an incidence of $1.4 \%$ and $0.3 \%$. Incidence of eclampsia in the hospitals of developing country is higher than the other part of the globe. The incidence of Eclampsia in Bangladesh is $3.2 \%$. In Kerla is $3.8 \%, 4.9 \%$ in Andra Pradesh, $15 \%$ in Madya Pradesh and $20.7 \%$ in Bihar [24]. These figures are higher compare to developed countries. Even in countries where pregnancy monitoring is considered good, eclampsia is not an uncommon pathology: its incidence is about 2.5 to $3.10-5$ in Sweden or Great Britain and higher in the United States at 1210-5 [9]. In France, G. Ducarme and colleagues found an incidence of eclampsia of $0.8 \%$ per year [10]. The risk factors for eclampsia are similar to those of preeclampsia without other specificities. They are abundantly described in literature but do not enable the detection of women at risk. The absence of risk factors does not eliminate the possibility of presenting with the complication. The main risk factors are young age and the lack of medical follow-up during pregnancy. Therefore, the surveillance of pregnant women remains the best weapon of prevention, as it makes it possible to detect the onset of pregnancy-related hypertension and pre-eclampsia [11]. Indeed in our study the high incidence of eclampsia compared to the developed countries is certainly related to the low percentage of medical monitoring of our parturients, which was $7.8 \%$. In our study, as also found in literature, eclampsia presents itself as a pathology of young primiparous women [12]. Eclampsia is a complication of pre-eclampsia that is secondary to a defect of trophoblastic invasion in the myometrium during placentation, leading to a lack of tissue oxygenation. This pathology can therefore occur throughout the peripartum period from the twentieth week of amenorrhea. Most cases of eclampsia occur pre- or peripartum, often before arrival at the hospital [13]. Early onset eclampsia (before the 32nd week of amenorrhea) seems to have a poorer prognosis [14]. Postpartum eclampsia occurs most often within 48 hours, but sometimes much later. For some, these cases of postpartum eclampsia are less serious in terms of associated pathologies (HRP, HELLP) [14]. In our study, eclampsia is usually established prepartum and there is no statistically significant relationship between 
postpartum eclampsia and decreased maternal complications. However, it should be noted that in prepartum eclampsia the use of $\mathrm{SMgO} 4$ promotes the neuroprotection in prematurity before the $33 \mathrm{rd}$ week of gestation, hence the importance of the use of this molecule for prepartum eclampsia [15]. The choice of $\mathrm{SMgO} 4$ as first-line treatment for pre-partum eclampsia is justified for its antiepileptic properties, prevention of recurrent seizures, and neuroprotection for the fetal brain [15]. Its mechanism of action seems adapted to the pathophysiology of posterior reversible encephalopathy (PRES syndrome), which remains a rare event in the evolution of eclampsia [16]. In our series the management protocol certainly recommends the use of $\mathrm{SMgO} 4$ for cases of prepartum eclampsia, but our data have not made it possible to study its effects of fetal neuroprotection. The preferred route of childbirth remains, for many authors, a caesarean section [15] as was the case in our study. The choice of anesthetic technique for caesarean section in case of eclampsia remains controversial. General anesthesia has risks such as difficult intubation, inhalation, hypertensive response of laryngoscopy and intubation, and multiple drug interactions. Spinal anesthesia also has risks such as extensive motor block, convulsions during the procedure, increased sensitivity to vasopressors to correct hypotension and cerebral involvement due to dural puncture in case of severe intracranial hypertension [17]. In case of eclampsia, locoregional anesthesia is possible if the patient is conscious, has no neurological deficit, and has a stable clinical condition and no thrombosis. On the other hand, general anesthesia is recommended in case of subintractive convulsions with disturbances of consciousness. In this case, induction is performed with thiopental. Finally, pre-eclampsia is accompanied by an exacerbation of the edema of the upper respiratory tract. These women must therefore be considered systematically as at risk for difficult intubation and laryngeal obstruction for extubation [18]. Finally, rapid evacuation of the uterus has been shown to significantly reduce maternal and infant mortality following eclampsia [2]. It is a systemic accident that is usually accompanied by a series of complications, making the prognosis even more unfavorable. Coagulopathy (15.6\%), HELLP syndrome (11.7\%), acute renal failure $(13.7 \%)$, and stroke $(1.9 \%)$ are often found by other authors; their frequency seems to be high in antepartum [19]. But rather than considering isolated complications, it is the associations of complications that are real prognostic factors of mortality. In our study the IRA-Hellp syndrome pair was significantly associated with mortality ( $\mathrm{p}<0.05$ ). Maternal mortality linked to eclampsia is currently low in European countries (between 0 and 1.8\%) thanks to rapid and adapted care, but varies between 14 and $15.6 \%$ in developing countries [11]. In a review of four different studies presented at the First International Conference of Obstetrics and Gynecology held in Bangladesh, perinatal mortality in eclampsia varied from (31 to $41) \%$ [20], and it appeared very high in comparison to general perinatal mortality rate in Bangladesh which at present is 70 per thousand livebirths [22]. In developed country, perinatal mortality in pre-eclampsia varied from 35 to 160/10005. Hypertensive expectant mothers (or gravidas) are predisposed to the development of petentially lethal complications of pregnancy notably abruptio placentae, disseminated intravascular coagulation cerebral haemorrhage hepatic failure and acute renal failure. Perinatal death was very high in our study compared to Baha ${ }^{e e}$ s [23] study (11.8\%). But in Bangladesh in several studies perinatal death were $32.1 \% 7,28 \% 8$ and $26.8 \%$ [22]. However, in our center in particular and in Bangladesh, the improvement of technical platforms, and medical follow-up of the parturients are prerequisites for the improvement of the prognosis of eclampsia. The prognosis of the newborn is directly related to gestational age and postnatal care [11]. Perinatal mortality and morbidity are still high with perinatal mortality ranging between 6 and $11.8 \%$ (versus $9.8 \%$ for our study) which is mainly related to the complications of induced prematurity, Retroplacental Hematoma (HRP) and Intra-Uterine Growth Delay (IUGR) [11].

\section{Conclusion}

Eclampsia remains common in developing countries. It is still responsible for high maternal and child mortality. The association of two or more serious factors is especially important concerning the mortality. Improving the prognosis involves prevention with early and regular monitoring of pregnancy, and early management of pre-eclampsia and eclampsia before the presentation of clinical symptoms. Finally, a multidisciplinary approach, with a greater participation of anesthesiologists-resuscitators, and the creation of specialized fields in anesthesia-obstetrics and neonatal resuscitation are needed in developing countries.

\section{REFERENCES}

1. Rivière, M. (1959). Mortalité maternelle au cours de l'état gravido-puerpéral, avortement excepté. Introduction générale. Rev. Franç. Gynecol. Obstét, 11, 141-143.

2. Beye, M. D., Diouf, E., Kane, O., Ndoye, M. D., Seydi, A., Ndiaye, P. I., \& Sall, B. K. (2003, January). Prise en charge de l'éclampsie grave en réanimation en milieu tropical africain. À propos de 28 cas. In Annales françaises d'anesthésie et de réanimation (Vol. 22, No. 1, pp. 25-29). Elsevier Masson.

3. Cantwell, R., Clutton-Brock, T., Cooper, G., Dawson, A., Drife, J., Garrod, D., ... \& MillwardSadler, H. (2011). Saving mothers' lives: reviewing maternal deaths to make motherhood safer: 2006-2008. The eighth report of the confidential enquiries into maternal deaths in the 
United Kingdom. BJOG: an international journal of obstetrics and gynaecology, 118, 1 .

4. Lewis, G. (ed). (2007). The Confidential Enquiry into Maternal and Child Health (CEMACH). Saving Mothers' Lives: Reviewing Maternal Deaths to Make Motherhood Safer - 2003-2005. The Seventh report on Confidential Enquiries into Maternal Deaths in the United Kingdom. London: CEMACH.

5. Endorsed by the European Society of Gynecology (ESG), the Association for European Paediatric Cardiology (AEPC), and the German Society for Gender Medicine (DGesGM), Authors/Task Force Members, Regitz-Zagrosek, V., Blomstrom Lundqvist, C., Borghi, C., Cifkova, R., ... \& Gorenek, B. (2011). ESC Guidelines on the management of cardiovascular diseases during pregnancy: the Task Force on the Management of Cardiovascular Diseases during Pregnancy of the European Society of Cardiology (ESC). European heart journal, 32(24), 3147-3197.

6. Lennox, C., \& Marr, L. (2011). Scottish confidential audit of severe maternal morbidity: 7th annual report 2009. Healthcare Improvement Scotland: Scotland.

7. Khan, K. S., Wojdyla, D., Say, L., Gülmezoglu, A. M., \& Van Look, P. F. (2006). WHO analysis of causes of maternal death: a systematic review. The lancet, 367(9516), 1066-1074.

8. Pambou, O., Ekoundzola, J. R., Malanda, J. P., \& Buambo, S. (1999). Prise en charge et pronostic de l'éclampsie au CHU de Brazzaville. Médecine d'Afrique noire, 46(11).

9. Collange, O., Launoy, A., Kopf-Pottecher, A., Dietemann, J. L., \& Pottecher, T. Iconography: Éclampsie. InAnnales françaises d'anesthésie ET de réanimation, 29(4), e75-e82.

10. Ducarme, G., Herrnberger, S., Pharisien, I., Carbillon, L., \& Uzan, M. (2008). Eclampsia: retrospective study about 16 cases. Gynecologie, obstetrique \& fertilite, 37(1), 11-17.

11. Raphael, V., \& Levasseur, J. (2007). Éclampsie. Encyclopedie medico-chirurgicale. 25-70.

12. Mellier, G., Miellet, C., Griot, J. P., \& Perrot, D. (1984). L'éclampsie: analyse d'une série de 18 observations. Conduite à tenir devant une crise grave. Revue française de gynécologie et d'obstétrique, 79(4), 271-275.

13. Sobande, A. A., Eskandar, M., Bahar, A., \& Abusham, A. (2007). Severe pre-eclampsia and eclampsia in Abha, the south west region of Saudi Arabia. Journal of obstetrics and gynaecology, 27(2), 150-154.

14. Mattar, F., \& Sibai, B. M. (2000). EclampsiaVIII. Risk factors for maternal morbidity. American journal of obstetrics and gynecology, 182(2), 307312.

15. Naeimi, A., Rieu, M., Le Guen, F., \& Marpeau, L. (2014). Sulfate de magnésium en prévention de l'éclampsie. À propos de 105 cas. Gynécologie Obstétrique \& Fertilité, 42(5), 322-324.

16. Araqi-Houssaini, A., Salmi, S., Moussaid, I., Guennoun, M. A., Elyoussoufi, S., Miguil, M., ... \& Slassi, I. (2011). Posterior reversible encephalopathy syndrome and eclampsia: a descriptive study of 13 cases in Morocco. Revue neurologique, 167(11), 812.

17. Doumiri, M., Ouandaogo, S., Oudghiri, N., \& Tazi, A. S. (2015). Rachianesthésie pour césarienne dans l'éclampsie stable. Anesthésie \& Réanimation, 1, A386.

18. Sprunck, A., Collange, O., \& Pottecher, T. (2009). Pré-éclampsie, éclampsie, HELLP syndrome: définitions, éléments de diagnostic et de prise en charge. 51e Congrès national d'anesthésie et de réanimation. Médecins. Urgences vitales, 1-9.

19. Diouf, A. A., Diallo, M., Mbaye, M., Sarr, S. D., Faye-Diémé, M. E., Moreau, J. C., \& Diouf, A. (2014). Profil épidémiologique et prise en charge de l'éclampsie au Sénégal: à propos de 62 cas. Pan African Medical Journal, 16(1).

20. Datta, D. C. (1998). Textbook of obstetric including perinatilogy and contraception. 4th ed. Calcutta. 51: 236-9, 648-9.

21. Robson, S. C. (1999). Hypertensiona and renal disease in pregnancy. In: Edmonds DK, editor. Dewhurst $^{\text {ee }} \mathrm{s}$ text book of obstetrics and gynaecology for postgraduates. 6th ed. London: Blackwell Science Lt., 166-77.

22. Rao, K. B. (1997). Perinatal mortality. In: Ratnam, S. S., Rao, K. B., \& Kumaran, S. A. Obsterics and gyanaecology for postgraduates. Vol. 2, 1st ed. Chennai: Orient Longman Ltd. 20:252-9.

23. Shamsuddin, L., Rouf, S., \& Khatoon, H. (1995). Perinatal outcome in eclampsia. Bangladesh $J$ obstet gynaecol. 10:65-72.

24. Sontakke, P., Reshmi, R. S., \& Sebastian, D. (2009). Obstetric morbidity among currently married women in selected states of India. The journal of family welfare, 55(2), 17-26. 